BANCA D'ITALIA

E U R O S I S T E M A

Questioni di Economia e Finanza

(Occasional Papers)

Goods exports and soft export indicators: is a disconneet under way?

by Claire Gíordano 

13 BANCA D'ITALIA

E U ROS I S T E M A

\section{Questioni di Economia e Finanza}

(Occasional Papers)

Goods exports and soft export indicators:

is a disconnect under way?

by Claire Giordano

Number 553 - March 2020 
The series Occasional Papers presents studies and documents on issues pertaining to the institutional tasks of the Bank of Italy and the Eurosystem. The Occasional Papers appear alongside the Working Papers series which are specifically aimed at providing original contributions to economic research.

The Occasional Papers include studies conducted within the Bank of Italy, sometimes in cooperation with the Eurosystem or other institutions. The views expressed in the studies are those of the authors and do not involve the responsibility of the institutions to which they belong.

The series is available online at wwm. bancaditalia.it.

ISSN $1972-6627$ (print)

ISSN 1972-6643 (online)

Printed by the Printing and Publishing Division of the Bank of Italy 


\title{
GOODS EXPORTS AND SOFT EXPORT INDICATORS: \\ IS A DISCONNECT UNDER WAY?
}

\author{
by Claire Giordano*
}

\begin{abstract}
We find evidence of a gradual weakening of the correlation between the new export orders component of the manufacturing purchasing managers' index (PMI) and real goods export dynamics in the four major euro-area countries since 2012. In Italy this disconnect has been particularly strong over the last few quarters and concerns other soft export indicators as well. The decline in the information content of firms' survey responses has gone hand in hand with several economic factors common to all four countries, such as a significant rise in economic uncertainty and the growing role of infra-group transactions within multinational enterprises.
\end{abstract}

JEL Classification: F00, F19.

Keywords: national accounts, goods exports, soft indicators.

DOI: $10.32057 / 0 . Q E F .2020 .553$

\section{Contents}

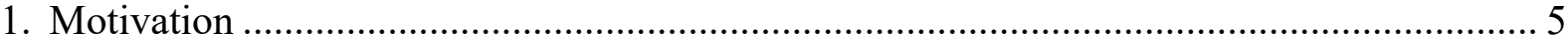

2. Is there a disconnect in the four main euro-area countries? ............................................ 5

3. Is Italy's disconnect common to other soft export indicators? ........................................... 9

4. Potential explanations for the recent disconnect …........................................................ 11

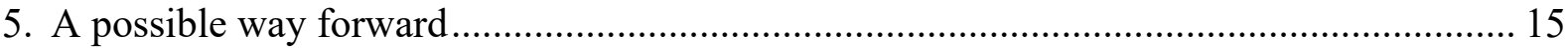

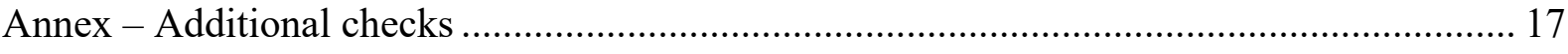

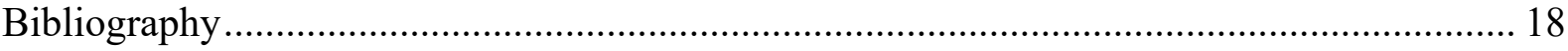

\footnotetext{
* Bank of Italy, DG for Economics, Statistics and Research, Balance of Payments Analysis Division.
} 



\section{Motivation ${ }^{1}$}

Amongst a range of soft indicators capable of timely tracking quarterly developments in Italy's goods exports, the "new export orders" component underlying the monthly Purchasing Managers' Index (PMI) is monitored in both the Bank of Italy's internal reports and in its official publications. While national accounts release export data with a 60-day delay relative to the reference quarter, Markit publishes its monthly PMI at the beginning of the month following the reference period. The new export orders indicator (hereafter referred to simply as PMI for brevity) is based on the replies of a sample of manufacturing firms (approximately 400), which are asked to compare the direction of change of foreign orders relative to the previous month. The resulting indicator is a seasonallyadjusted diffusion index ranging between 0 and 100: 50 is the threshold of unvaried conditions, and values larger (smaller) than 50 signal an increase (a decrease) with respect to the previous period. ${ }^{2}$

Developments of the volume of goods exports and those of the PMI have been noticeably diverging in Italy in recent quarters. This note investigates: (a) when this apparent decoupling began to emerge and whether it is common also to the other three large euro-area economies; (b) whether in Italy other soft indicators are also diverging relative to the same variable; (c) some candidate explanations of this disconnect; d) a possible way forward in our short-term economic outlook analysis for Italy.

\section{Is there a disconnect in the four main euro-area countries?}

We compare $q-0-q$ changes in the volume of goods exports with the contemporaneous quarterly average PMI; both variables are stationary and hence comparable. We here only consider contemporaneous correlations since they turn out to be the largest empirically, despite the fact that order components are conceptually leading indicators. ${ }^{3}$ On average over the 1999Q1-2019Q2 period the PMI is found to be significantly correlated with export dynamics in Italy (0.63), but also in France (0.66) and in Germany (0.69; Fig. 1); PMI series for Spain are only available since 2008.

These overall correlations, however, mask significant heterogeneity over time. Focusing our attention on the most recent years, this relationship has weakened in all four countries roughly since the outbreak of the sovereign debt crisis in 2012. Indeed, in the 2012Q1-2019Q2 sub-period the afore-mentioned correlation dropped, especially in Italy (to 0.04 , as in Spain, against 0.24 in France and 0.28 in Germany). In particular, as of 2018Q2 in Italy the PMI has been signalling a decline in foreign sales, when actually the latter have continued to expand.

\footnotetext{
${ }^{1}$ The Author thanks Andrea Brandolini, Luigi Federico Signorini and several colleagues of the Balance of Payments Analysis and of the Economic Outlook Divisions for their useful comments on previous drafts, as well as Giuseppe Casubolo and Roberto Marano for editorial assistance.

${ }^{2}$ The diffusion index is constructed as a simple weighted average of the aggregate "increase" and "unchanged" response shares with weights 1 and 0.5 , respectively.

${ }^{3}$ One possible explanation of why contemporaneous, as opposed to lagged, correlations are higher is the following: the PMI is a monthly indicator, with expectations based on a comparison with the previous month. The figure referring to the first month of a quarter is hence intrinsically partially leading relative to actual exports recorded by national accounts in the same quarter; the average quarterly PMI is slightly leading as a result.
} 


\section{Short-term changes in the volume of goods exports and the contemporaneous PMI new export orders component}

( $q-0-q$ percentage changes in real goods exports; seasonally-adjusted quarterly averages of PMIs minus 50)

Italy

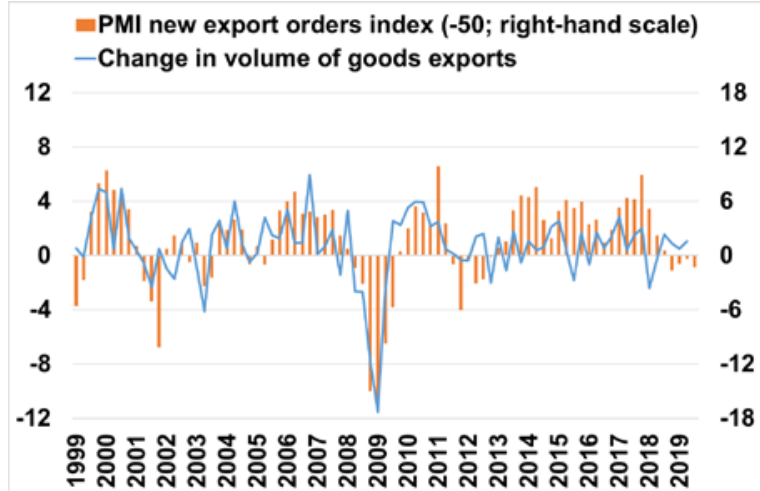

Germany

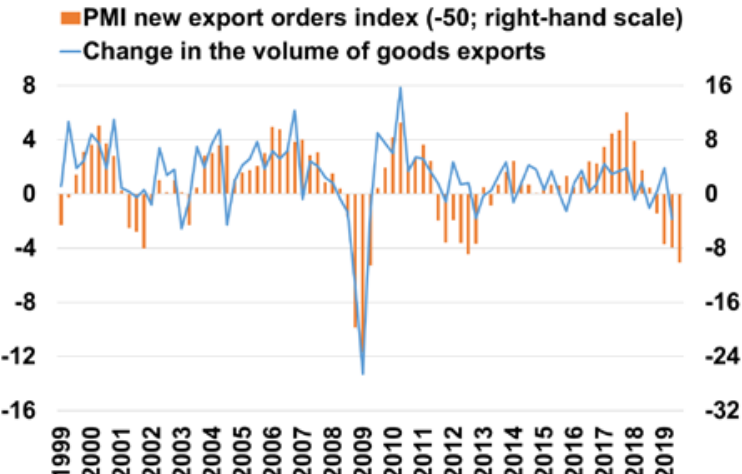

France

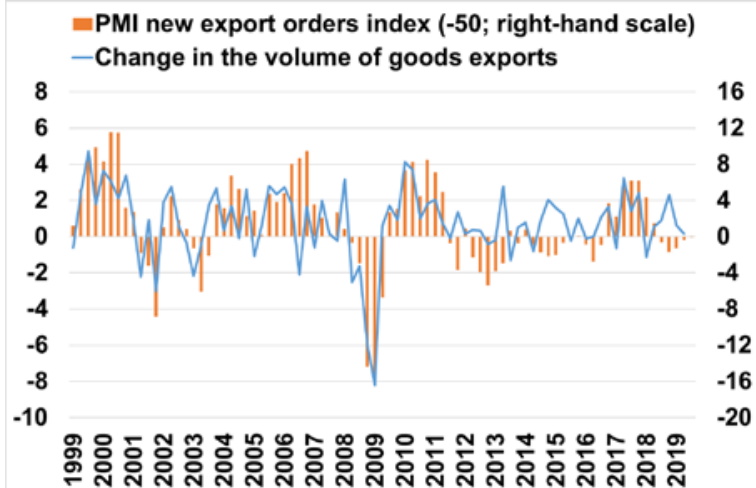

Spain

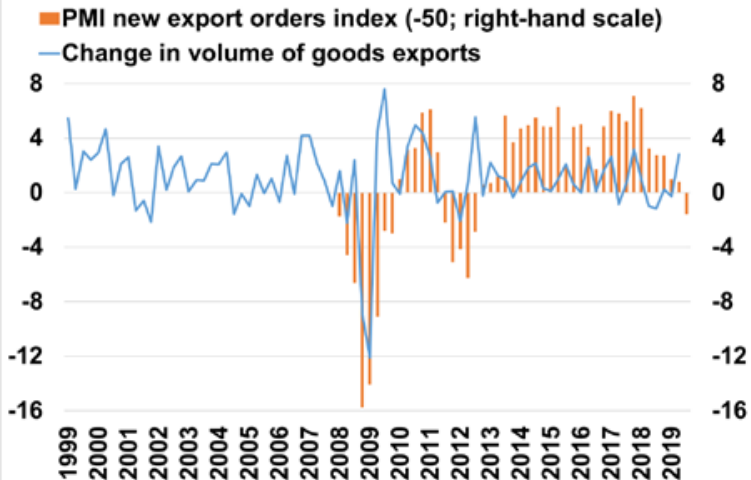

Source: Eurostat for national account data and Markit for PMI series.

This evidence is confirmed when we compute the contemporaneous correlation coefficient between the q-o-q growth rate of real goods exports and the PMI based on three or five-year rolling windows (Fig. 2). A first disconnect may be observed in the years immediately running up to the global financial crisis, when this coefficient significantly declined, yet remaining at higher values in Italy than in France and Germany. During the crisis years, as well as in the subsequent immediate recovery, the link between the two variables tightened in all countries, reaching values larger than 0.8 . The correlation coefficient then shrank once again, more decisively and across the board, before recording a slight recovery as of 2016-2017. It is noteworthy that the correlation in Italy, however measured, is currently the lowest across the four economies. ${ }^{4}$

${ }^{4}$ Similarly, Guglielminetti (2018) provides evidence of a decoupling between the manufacturing PMI and the industrial production index in Italy, both in the early 2000 s and after the sovereign debt crisis. 


\section{Contemporaneous correlation between short-term changes in the volume of goods exports and the PMI new export orders component}

(quarterly data)

Three-year rolling windows

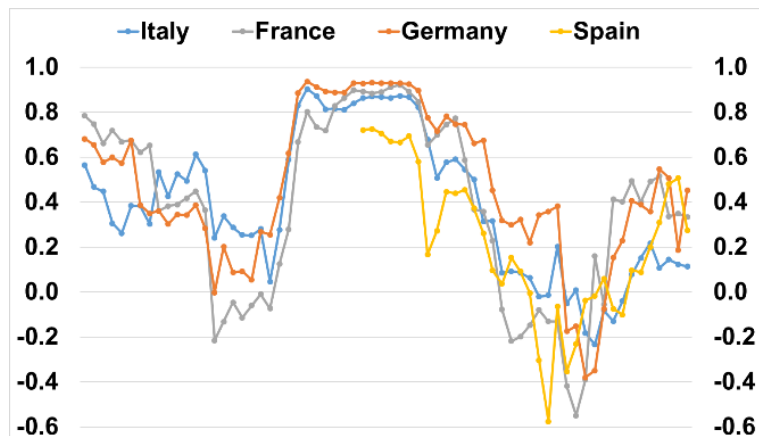

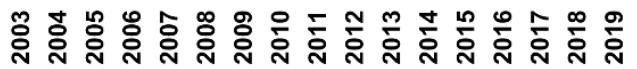

Five-year rolling windows

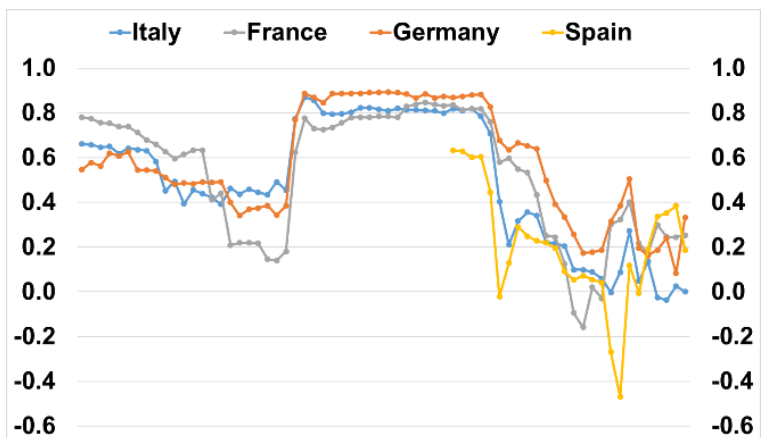

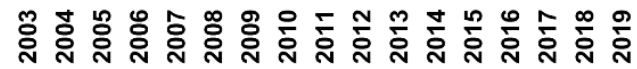

Source: author's calculations on Eurostat and Markit data.

It has been claimed that PMI respondents give answers conveying information about the underlying tendency of economic activity rather than the latest monthly variations. ${ }^{5}$ In the Annex we show that the presence of the disconnect in the four countries under study is also present if we consider $\mathrm{y}-\mathrm{o}-\mathrm{y}$, as opposed to $\mathrm{q}-\mathrm{o}-\mathrm{q}$, changes in exports.

These qualitative results are also corroborated by a more formal, quantitative analysis based on Granger causality tests. The question investigated here is whether the PMI new export orders index (noted by $x$ ) can help forecast q-o-q changes in the volume of goods exports (noted by $\Delta y$ ). ${ }^{6}$ More formally, restricting ourselves to linear functions and dropping the country subscript $i$ for simplicity, we estimate the following model using ordinary least squares for each of the four euroarea countries:

$$
\Delta y_{t}=c_{1}+\alpha_{1} \Delta y_{t-1}+\cdots+\alpha_{p} \Delta y_{t-p}+\beta_{1} x_{t-1}+\cdots+\beta_{p} x_{t-p}+\varepsilon_{t}
$$

where $c_{1}$ is a constant, $p$ is the autoregressive lag length (selected in order to maximise the fit of the equation) and $\varepsilon_{t}$ is the error term. We then conduct an $\mathrm{F}$ test of the null hypothesis:

$$
H_{0:} \beta_{1}=\cdots=\beta_{p}=0
$$

Rejection of the null hypothesis implies that $x$ Granger-causes $\Delta y$.

Table 1 reports the results of the Granger causality tests, in particular the F statistic and its corresponding $\mathrm{p}$-value, for each country both over the entire 1999Q1-2019Q2 period and over the more recent 2012Q1-2019Q2 sub-period. Over the entire period the null hypothesis is rejected for all three countries for which the data are available, implying that the PMI does indeed Granger-cause q-o-q export dynamics. However, for the period since 2012 the null hypothesis cannot be rejected,

${ }^{5}$ See Aprigliano (2011) and references therein.

${ }^{6}$ This is the case if the mean squared error (MSE) of the forecast of $\Delta y_{t}$ based solely on the p-order lags of $\Delta y_{t}$ is strictly larger than the MSE of the forecast of $\Delta y_{t}$ that uses both the p-order lags of $\Delta y_{t}$ and of $x_{t}$. 
Granger causality test results

\begin{tabular}{|l|cc|}
\hline & 1999Q1-2019Q2 & 2012Q1-2019Q2 \\
\hline \multirow{2}{*}{ Italy } & $\mathbf{3 . 1 6}$ & 0.26 \\
& 0.0293 & 0.8548 \\
France & $\mathbf{4 . 2 3}$ & 0.33 \\
& 0.0181 & 0.7225 \\
Germany & $\mathbf{9 . 7 5}$ & 0.54 \\
& 0.0002 & 0.5878 \\
Spain & - & $\mathbf{2 . 4 7}$ \\
& - & 0.0898 \\
\hline
\end{tabular}

Source: author's estimates.

Notes: For each country F-statistics are reported together with their corresponding $p$-values (in small font). Lag order $p$ is three in the case of Italy and Spain, two in the case of France and Germany. Figures highlighted in bold flag rejection of the null hypothesis reported in equation (2).

It has been argued that PMls capture the sign of changes in the target variable rather than the intensity of its variations (Conti and Rondinelli, 2015). Table 2 hence reports the number of times there has been either sign concordance or discordance between the two variables. Over the entire period sign concordance was high in France, Germany and Italy (on average in 59 out of 82 quarters, i.e. 72 per cent of cases). In the case of discordance, positive surprises (i.e. cases in which the PMI was lower than 50 and the change in the volume of goods exports was positive) were more frequent than negative surprises (i.e. cases in which the PMI was higher than 50 and the change in exports was negative).

The frequency of sign concordance dropped across the board in the post-2012 period; concordance was indeed recorded on average in the four countries in 18 out of 30 quarters (i.e. 59 per cent of cases). In Spain negative surprises were more frequent than positive ones; the converse holds true in France, whereas in Italy and Germany the frequency of these two outcomes was comparable. It is noteworthy, however, that in the case of Italy four out of the five post-2012 "positive surprise" episodes occurred in the four most recent quarters.

\footnotetext{
7 The PMI is found to Granger-cause export changes in Spain in the restricted period 2012Q1-2019Q2, but we are not able to compare the strength of this result to that obtained over the whole period, since PMI data for Spain only start is 2008 , as mentioned earlier.
} 


\section{Sign concordance/discordance between short-term changes in the volume of goods exports and the PMI new export orders component}

(number of quarters)

1999Q1-2019Q2

\begin{tabular}{|c|c|c|}
\hline & $\begin{array}{c}\text { Positive sign } \\
\text { concordance } \\
(\mathrm{PMI}>50 ; \Delta \mathrm{X}>0)\end{array}$ & $\begin{array}{c}\text { Sign } \\
\text { discordancel } \\
\text { positive surprise } \\
(\mathrm{PMI}<50 ; \Delta \mathrm{X}>0)\end{array}$ \\
\hline Italy & 47 & 12 \\
\hline France & 40 & 18 \\
\hline Germany & 52 & 11 \\
\hline Spain & - & - \\
\hline & $\begin{array}{c}\text { Sign } \\
\text { discordancel } \\
\text { negative } \\
\text { surprise } \\
(\mathrm{PMI}>50 ; \Delta \mathrm{X}<0)\end{array}$ & $\begin{array}{c}\text { Negative sign } \\
\text { concordance } \\
(\mathrm{PMI}<50 ; \Delta \mathrm{X}<0)\end{array}$ \\
\hline Italy & 10 & 13 \\
\hline France & 10 & 14 \\
\hline Germany & 9 & 10 \\
\hline Spain & - & - \\
\hline
\end{tabular}

2012Q1-2019Q2

\begin{tabular}{|c|c|c|}
\hline & $\begin{array}{c}\text { Positive sign } \\
\text { concordance } \\
(\mathrm{PMI}>50 ; \Delta \mathrm{X}>0)\end{array}$ & $\begin{array}{c}\text { Sign } \\
\text { discordancel } \\
\text { positive surprise } \\
(\mathrm{PMI}<50 ; \Delta \mathrm{X}>0)\end{array}$ \\
\hline Italy & 17 & 5 \\
\hline France & 8 & 14 \\
\hline Germany & 17 & 6 \\
\hline Spain & 20 & 2 \\
\hline & $\begin{array}{c}\text { Sign } \\
\text { discordancel } \\
\text { negative } \\
\text { surprise } \\
(\mathrm{PMI}>50 ; \Delta \mathrm{X}<0)\end{array}$ & $\begin{array}{l}\text { Negative sign } \\
\text { concordance } \\
(\mathrm{PMI}<50 ; \Delta \mathrm{X}<0)\end{array}$ \\
\hline Italy & 6 & 2 \\
\hline France & 3 & 5 \\
\hline Germany & 5 & 2 \\
\hline Spain & 7 & 1 \\
\hline
\end{tabular}

Source: author's calculations on Eurostat and Markit data.

In sum, as of 2012 the PMI's ability of tracking the intensity, or even only of capturing the sign, of actual goods export dynamics has gradually and significantly deteriorated in the main euroarea economies; this is especially true for Italy over the past year.

\section{Is Italy's disconnect common to other soft export indicators?}

We now investigate whether the observed disconnect for Italy is common to other qualitative export indicators. The first set of measures is sourced from Istat's monthly manufacturing business survey. In particular, we consider the (one-quarter ahead) seasonally-adjusted percentage-point balance of firm responses concerning opinions on foreign orders, available at a monthly frequency since 2000 , as well as that concerning opinions on foreign sales, available at a quarterly frequency since the same date. ${ }^{8}$ These two indicators appear to be highly correlated with the PMI (Fig. 3); hence, it is unsurprising that their contemporaneous correlations with q-o-q changes in the volume of goods exports, albeit significant over the whole period since 2000 (0.56 on average), are also found to drop to values close to zero in the 2012Q1-2019Q2 sub-period.

\footnotetext{
${ }^{8}$ It is noteworthy that the quarterly average balance of Istat's foreign orders index has always been negative since 2000. Moreover, we find that it is a lagging indicator of goods export dynamics (differently from the sales indicator which is coincident), so not particularly useful for nowcasting purposes. The Istat survey also contains a question on expectations of foreign sales, but this indicator weakly correlates with goods export developments, and hence is here not considered.
} 


\section{Short-term changes in the volume of goods exports, PMI and Istat export indicators in Italy}

(q-o-q percentage changes in real goods exports; seasonally-adjusted quarterly averages of PMIs minus 50; one-quarter ahead seasonally-adjusted quarterly average percentage-point balances of Istat export orders; seasonally-adjusted percentage-point balances of Istat export sales)

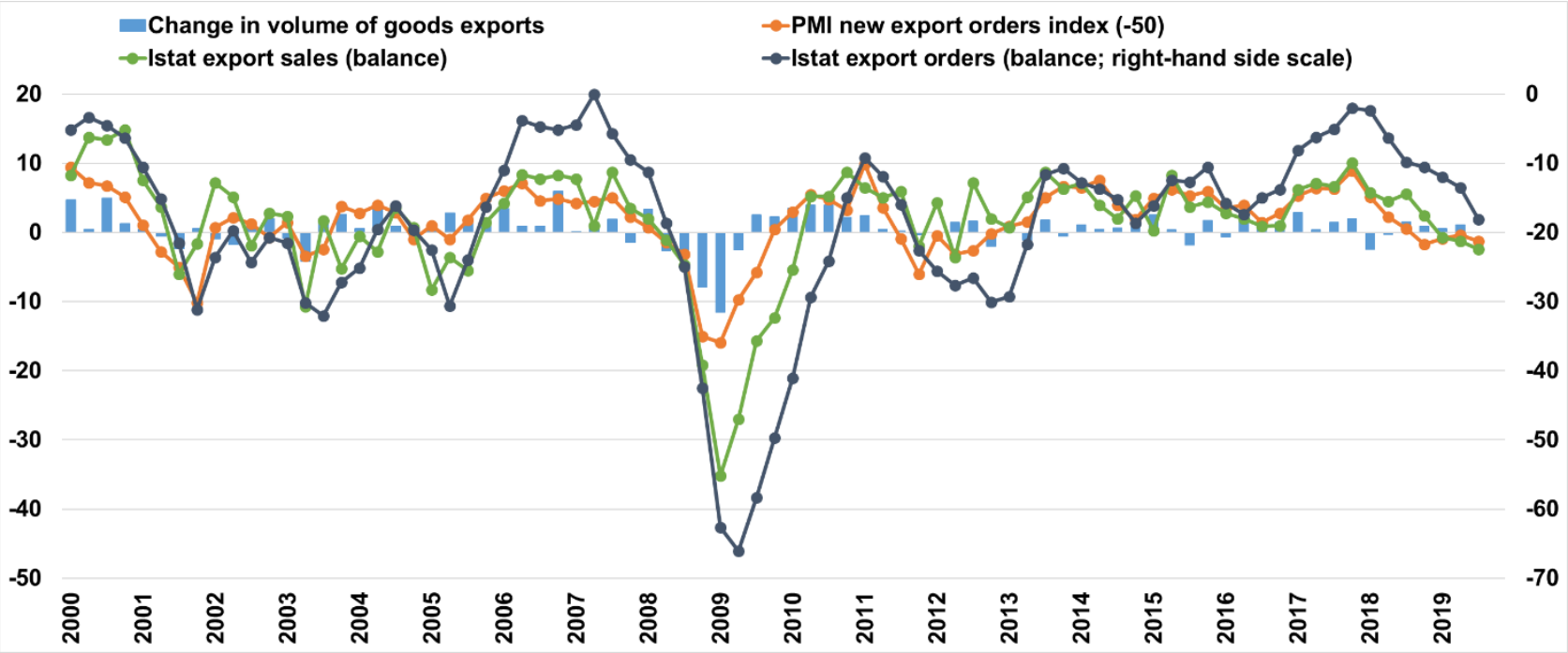

Source: author's calculations on Istat for national account and business survey data and Markit for PMI series.

The second set of soft indicators is based on the Bank of Italy's quarterly Survey on Inflation and Growth Expectations (IAI, using the Italian acronym) and, in particular, on (industrial net of construction) firms' opinions on changes in foreign demand for their products relative to the previous quarter. ${ }^{9}$ Time series for this variable are relatively short (2009Q3 onwards) compared with the indicators discussed previously, so we only consider the period since 2012 (Fig. 4). We compute both the balance and the diffusion index (similarly to the PMI, as explained in footnote 2). In this case too, the correlation of these indicators with the PMI is very high (0.84), and hence it is unsurprising that their correlation with goods export dynamics is extremely weak (0.10).

The post-2012 decoupling in Italy between soft export indicators and goods export changes is therefore not limited to PMI data, but is observable also for several other survey-based indicators. In particular, it is noteworthy that in the most recent quarters all these indicators were located in negative territory or were, at most, positive but negligible, despite the country's actual export expansion.

${ }^{9}$ IAI also contains a question on the expected change in foreign demand in the following quarter, but this variable correlates weakly with goods export changes, so we excluded it from this analysis. 


\section{Short-term changes in the volume of goods exports, PMI and Bank of Italy export indicators in Italy}

(q-o-q percentage changes in real goods exports; seasonally-adjusted quarterly averages of PMIs minus 50; seasonally-adjusted percentage-point balances and diffusion indices of IAI foreign demand opinions)

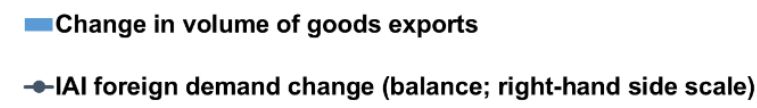

- IAI foreign demand change (balance; right-hand side scale)
- PMI new export orders index (-50)

$-\mid$ AI foreign demand change (diffusion index -50 )

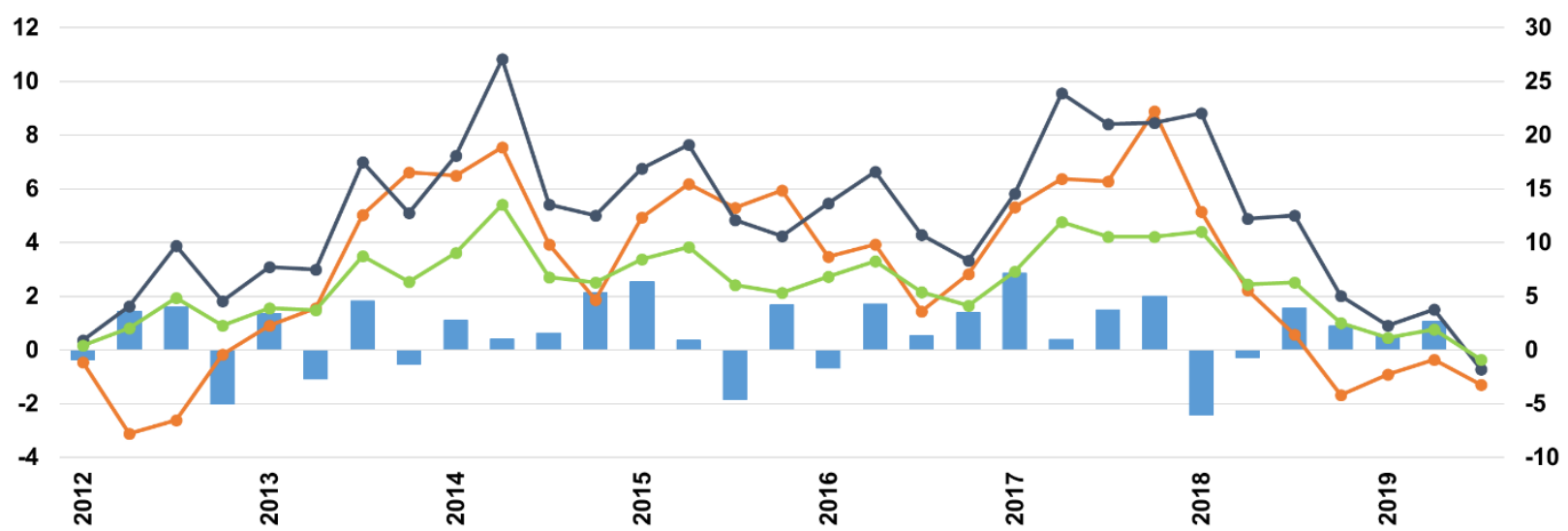

Source: author's calculations on Istat for national account data, Markit for PMI series and Bank of Italy for IAI data.

\section{Potential explanations for the recent disconnect}

Pinning down the causes of the observed recent divergence between qualitative indicators and actual export developments would require access to the underlying PMI micro-data, which are unavailable. However, in this section we discuss several factors that might be at play.

One possible technical explanation of the disconnect is that it is due to a change in the seasonality adjustment underlying the PMI. Unfortunately, raw PMI data are not available to investigate this possibility. However, the fact that this divergence is observed in all four euro-area countries under study, and that it is present also in the case of other (seasonally-adjusted) export indicators for Italy, leads us to exclude this hypothesis with a reasonable degree of confidence. ${ }^{10} \mathrm{We}$ hence move on to consider potential "economic" causes.

First, there is evidence of a significant rise in economic uncertainty, common to the four euroarea countries, in the post-2012 period, as measured by the Economic Policy Uncertainty (EPU)

${ }^{10}$ Differently to the PMI, the Istat export order indicator, plotted in Figure 3, is also available in seasonally unadjusted terms. The correlation between the unadjusted Istat measure and the unadjusted volume of goods exports is found to have significantly declined in the post-2012 period too, corroborating our view that seasonality issues are not a significant factor at play. 
Index (Fig. 5), sourced from Baker, Bloom and Davis (2016). ${ }^{11}$ This general heightened uncertainty ${ }^{12}$ may have contributed to cloud the economic outlook and hence make firm survey responses less informative of actual developments than in the past. This explanation is more likely for Italy and Germany, the two countries for which there is no evidence of a systematic sign bias in the observed decoupling, as documented in Section 2.

Figure 5

\section{The Economic Policy Uncertainty index in the four main euro-area countries} (quarterly averages)
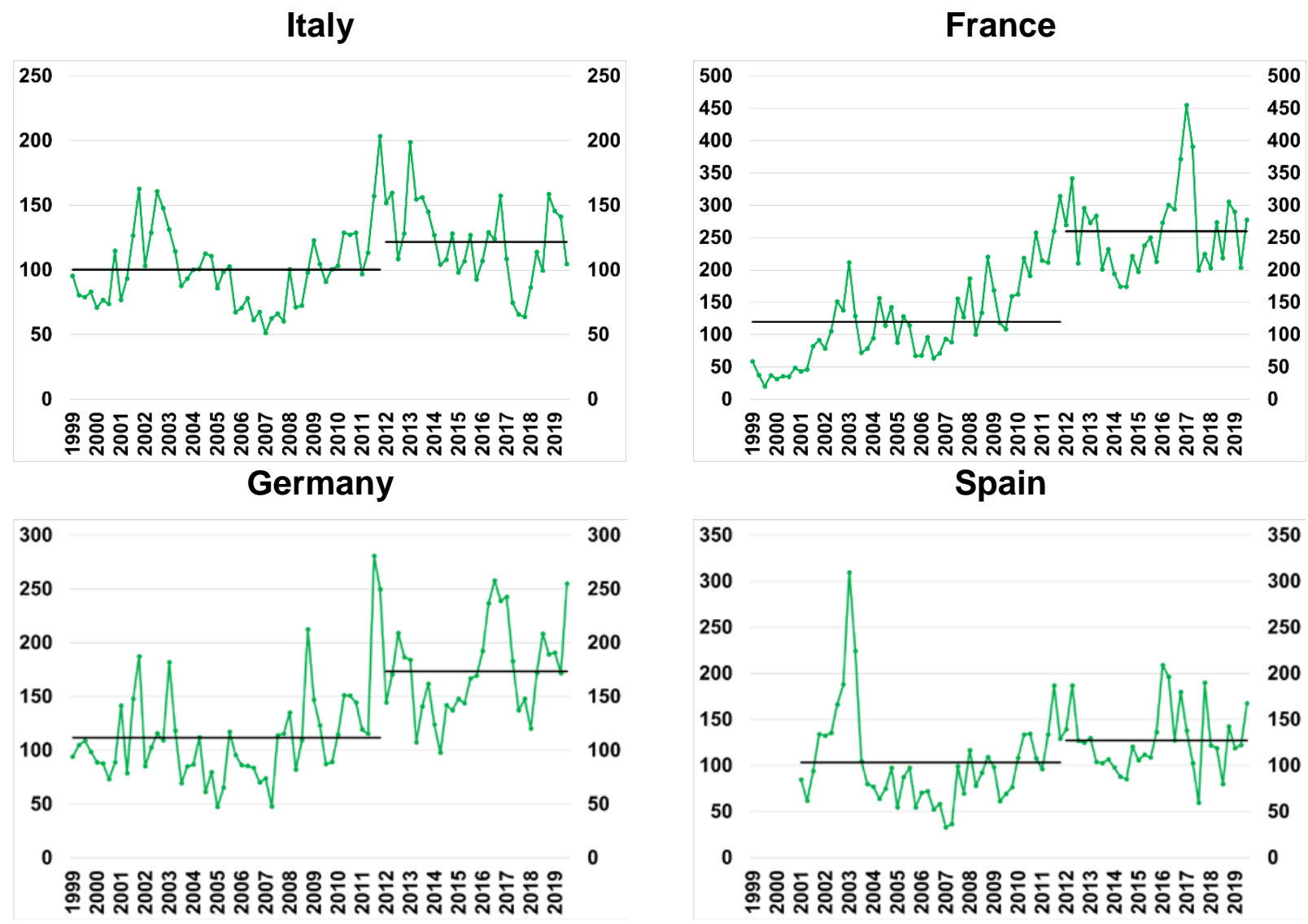

Spain

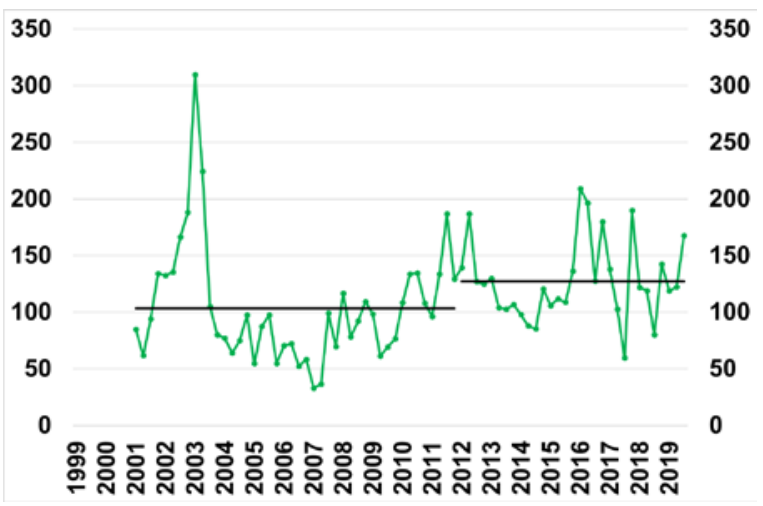

Source: www.PolicyUncertainty.com.

Notes: See footnote 11 for the methodology underlying the construction of this index.

An alternative, more micro-founded measure of uncertainty is given by the dispersion in the

${ }^{11}$ This measure is based on the number of articles containing the terms "uncertain" or "uncertainty", "economic" or "economy", and one or more policy-relevant words drawn from two main newspapers for each country (Le Monde and Le Figaro for France, Handelsblatt and Frankfurter Allgemeine Zeitung for Germany, Corriere Della Sera and La Repubblica for Italy, El Mundo and EI Pais for Spain). The raw EPU count is then scaled by the number of articles in the same newspaper and month. Each newspaper-level monthly series is then standardised to unit standard deviation prior to 2011 and averaged across newspapers by month to obtain country-level indices, which are normalized to a mean of 100 prior to 2011. The final index is an average of the two newspaper-level indices.

12 Some possible common underlying causes include the imposition of economic sanctions on various countries, conflicts and political turbulence in the Middle East, terror attacks in some euro-area countries, political uncertainty and instability due to elections in several large advanced economies, the growth slowdown in China, the Brexit referendum with its still uncertain resolution and the escalation of trade policy tensions under the current US administration (which are reflected in the very recent hike in the newly developed Trade Uncertainty Index, sourced from Ahir, Bloom and Furceri (2018), in all four euro-area countries). 
opinions of firms on relevant variables (e.g. Bachmann, Elstner and Sims, 2014; Busetti, Giordano and Zevi, 2016; Gamberoni, Giordano and Lopez-Garcia, 2016; Giordano, Marinucci and Silvestrini, 2019). In particular, this proxy is computed as $\sqrt{\mathrm{frac}_{t}^{+}+\mathrm{frac}_{t}^{-}-\left(\mathrm{frac}_{t}^{+}-\mathrm{frac}_{t}^{-}\right)^{2}}$, where $\mathrm{frac}_{t}^{+}$ and $\mathrm{frac}_{t}^{-}$are the fractions of firms with 'increase' and 'decrease' responses at time $t$. Markit does not release information on firms' response shares underlying the PMI, but these are available, for example, for the Bank of Italy's IAI, yet only for Italy. As mentioned in Section 3, IAI is available since the end of 2009, hence a comparison between pre- and post-2012 levels of uncertainty thus measured is not meaningful. However, we find evidence of an increase in the dispersion in firms' opinions on foreign demand dynamics since the second half of 2018, which is consistent with the widening of the soft export indicators-actual export dynamics gap observed for Italy in recent quarters.

Second, we check whether the weight of productions that require significant time and which are hence ordered well in advance relative to their delivery date have increased, thereby loosening the link between foreign orders and actual, contemporaneous exports. A typical example is means of transport other than auto-vehicles, such as ships, trains and airplanes. Table 3, however, does not provide strong support for this hypothesis, at least for the three countries for which the breakdown is readily available. Indeed, the share of these products on total exports is quite small across the board. Moreover, in Germany and Spain the weight of air and spacecraft sales has risen only moderately in the years 2012-2018 relative to previous sub-periods, and in Italy the share of ships and boats has actually fallen. ${ }^{13}$

A third factor, linked to the activities of multinational enterprises (MNEs), concerns the growth in intra-group trade flows in recent years, which again may contribute to the explanation of the general post-2012 disconnect. On the one hand, large intra-group transactions blur the informative content of the PMI if the surveyed managers base their responses solely on the development of extra-group, rather than overall, export orders. On the other hand, an increase in intra-group flows could affect the measurement of national account exports if infra- and extra-group transactions are priced differently. ${ }^{14}$ According to Istat's Foreign Affiliate Trade Statistics (FATS), the share of exports of foreign-owned industrial firms located in Italy went from 23.1 per cent of total exports in 2005 to 26.4 in 2016 (the last year for which FATS are currently available). Although these data only refer to Italy, since long time series are not readily available for other countries, it is reasonable to assume that this was a common development in all large euro-area economies. Furthermore, according to more detailed ICE-Istat data, available however for few years and again only for Italy, in the period 2012-2016 roughly two thirds of manufacturing exports were sold by foreign-owned and Italian MNEs resident in Italy. Focusing solely on foreign-owned MNEs, the share of infra-group exports rose significantly, from 43.0 per cent of total exports in 2012 to 51.7 per cent in 2016, further corroborating the view of the relevance of MNEs in explaining the documented disconnect.

\footnotetext{
13 This may not be the case for France, given the recent hike in Airbus orders (by 28 per cent in the years 2013-2018, according to data available at the company's website: https://www.airbus.com/newsroom/pressreleases/en/2019/01/airbus-achieves-new-commercial-aircraft-delivery-record-in-2018.html)

${ }^{14}$ Indeed, national accounts estimate export deflators according to export prices, which are based solely on extra-group transactions.
} 
The share of selected sectors' exports in total goods exports in Italy, Germany and Spain

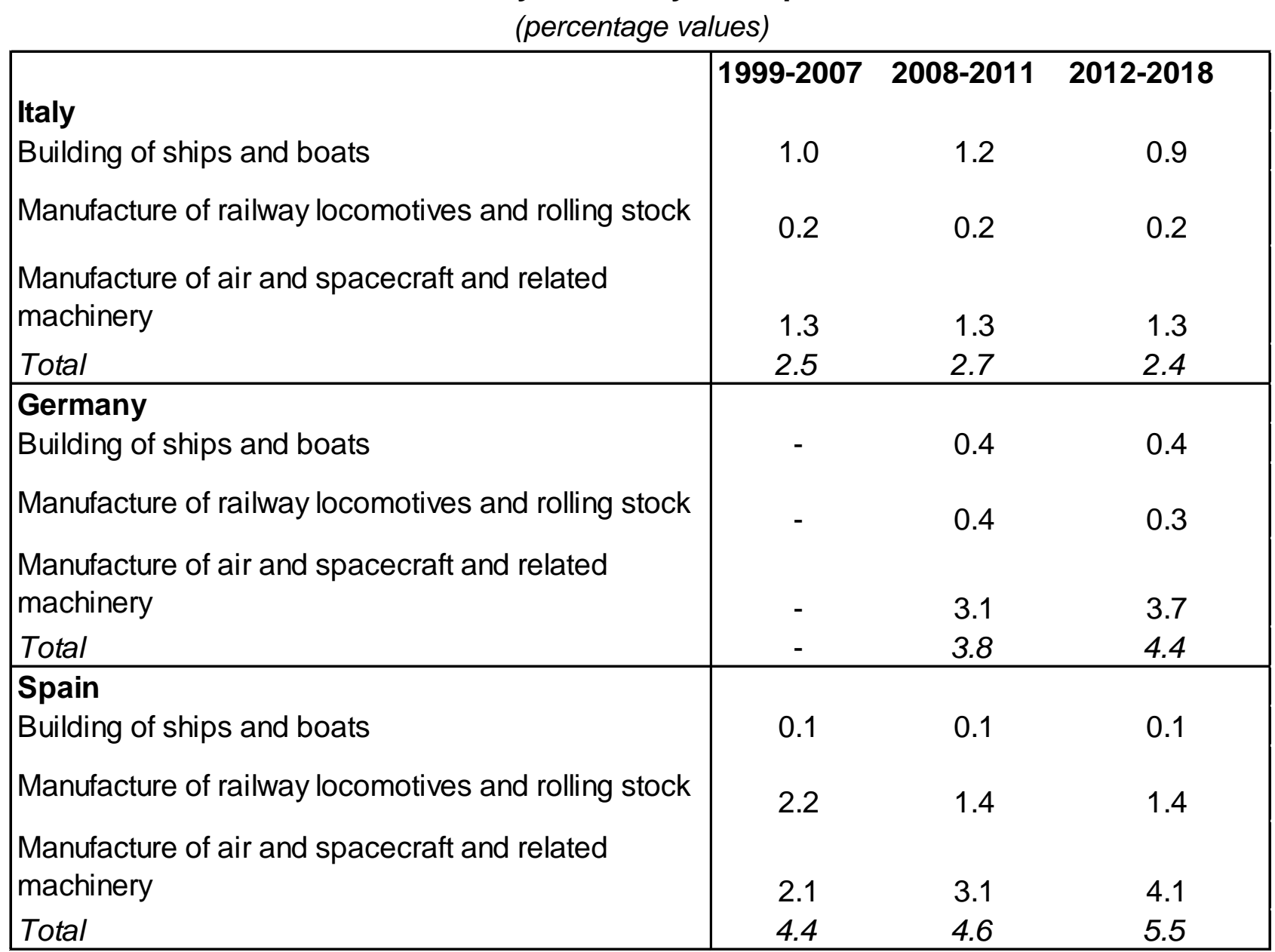

Source: author's calculations on Istat, Destatis and Secreteira de Estado de Comercio data.

Finally, as concerns the specific developments in Italy since 2018Q2, the relatively favourable export dynamics are largely explained by strong growth in foreign sales of the pharmaceutical sector. ${ }^{15}$ Figure 6 compares changes in the volume of total goods exports with those net of pharmaceutical products since 2010, showing how the two series have diverged in the last three quarters: goods export growth would have been broadly flat in Italy without the pharmaceutical sector's positive contribution, and hence more in line with the PMI information. The PMI survey panels are stratified according to sector and company workforce size; the importance of each strata in the overall panel is then decided by the contribution to total manufacturing value added (VA). However, since 2010 in Italy the VA of the pharmaceutical sector has grown significantly less than its exports. Had the importance of each strata been defined according to the contribution to total exports as opposed to VA, the representativeness of the pharmaceutical branch in the PMI sample would have been increasingly larger, in line with the rising stimulus of this sector to actual total goods exports. Hence, this sample design choice could also help to explain the loss in informative content of the PMI relative to actual goods export dynamics, in particular in Italy in the most recent quarters.

${ }^{15}$ Pharmaceutical exports have been recording pronounced dynamics in Italy since 2010 (Bugamelli et al, 2018), yet in recent quarters Italy's pharmaceutical external performance has been particularly favourable. 
Figure 6

\section{Short-term changes in the volume of total goods exports and of total goods exports net of the pharmaceutical sector in Italy since $\mathbf{2 0 1 0}$}

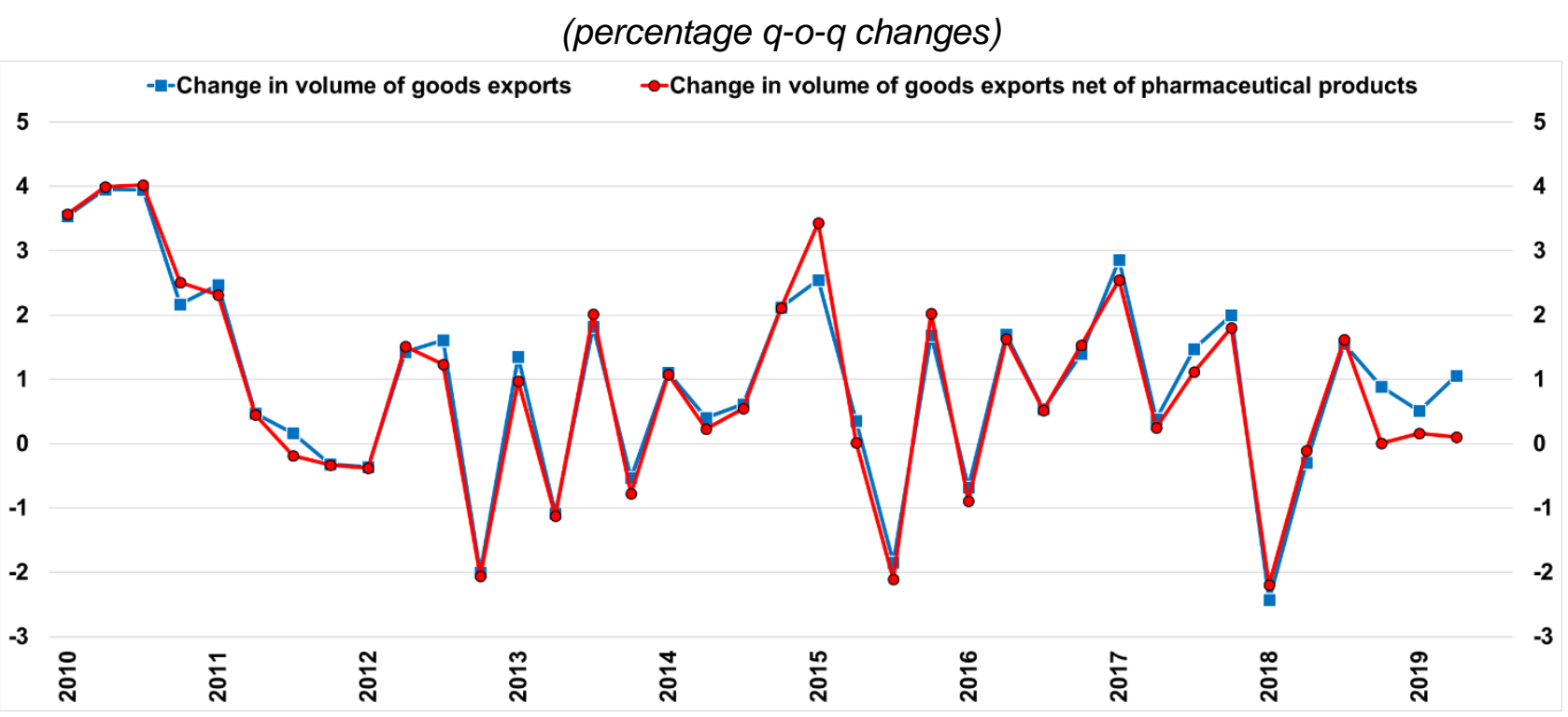

Source: author's calculations on Istat national account and trade data.

Notes: Sectoral producer price indices for goods sold in foreign markets (export prices) by sector are employed to deflate the sectoral trade flows.

\section{A possible way forward}

This preliminary investigation points to the need of considering a range of both soft and hard indicators in order to track current export developments in Italy, in a period of historically high macroeconomic uncertainty and of strong MNE expansion.

One option is the seasonally-adjusted industrial (net of construction) new foreign orders index, sourced from Istat's monthly Survey on sales and orders. This indicator is less timely than PMIs or the Istat business survey, in that it is published two months after the reference period, but it has the advantage of being a quantitative measure. We deflate this nominal index by the producer price index of goods sold in the foreign markets and estimate the value for the latest quarter (2019Q3) with the average of the first two months. The result is shown in Figure 7: a reasonable correlation with real goods export dynamics can be observed, even after 2012, when values are on average around 0.5. However, a disconnect and sign discordance may be seen in the most recent quarters also for this hard indicator, plausibly due to the afore-mentioned developments in the pharmaceutical sector. 


\section{The relationship between the volume of total goods exports and} the volume of new foreign industrial orders in Italy

(index 2005=100)

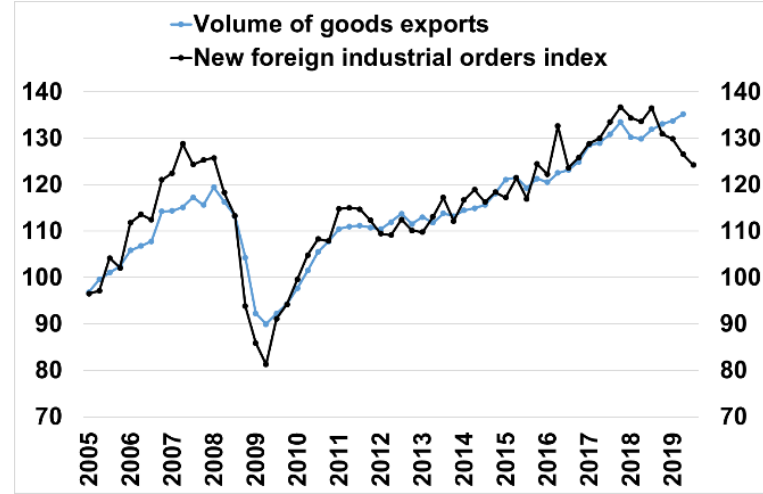

(three-year rolling-window contemporaneous correlation coefficient)

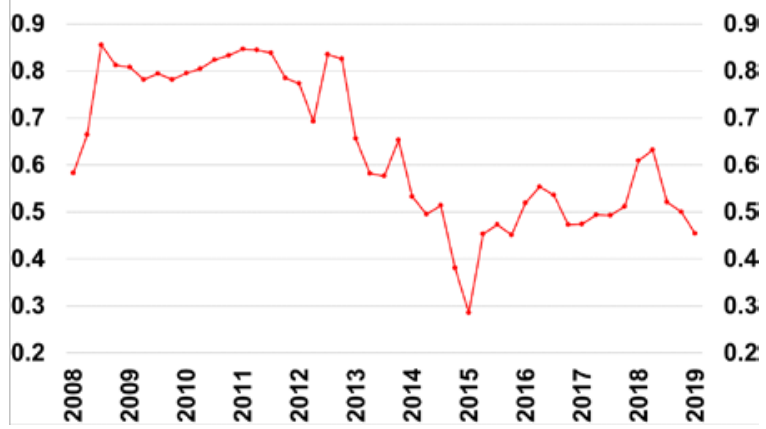

Source: author's calculations on Istat national account and Survey on sales and orders data.

Notes: The new foreign industrial orders index appraised at constant prices is obtained by deflating Istat's

seasonally-adjusted nominal measure by the producer price index of goods sold in foreign markets.

Another option is to better exploit the information underlying IAI. Although qualitative, this survey has the advantage of being timely. However, given the current IAI survey design, we are only able to track the number and/or weight of interviewed firms by 1-digit sector (for example, in total manufacturing), and not by 2-digit sector. This implies that we are unable to readily quantify, for example, the (possibly changing) representativeness of pharmaceutical firms in the survey sample. Moreover, we do not know if a firm operates within an MNE or not. Future work could invest in the construction of alternatively weighted indicators (e.g. by export sales) drawn from IAI data. 


\section{Annex - Additional checks}

It has been claimed that PMI respondents give answers conveying information about the underlying tendency of economic activity rather than the latest monthly variations. We therefore measure the correlation between the y-o-y real export change - in lieu of the q-o-q variations analysed in Section 2 - and the (one-quarter lagged) PMI export orders component. ${ }^{16}$ As seen in Figure A1, the link between the two variables is tighter across the board than that reported in Figure 1 ; indeed the correlation coefficients are $0.78-0.79$ over the entire period for France, Germany and Italy. However, this relationship too has visibly weakened as of 2012, and more so for Italy (the correlation coefficients indeed fall to 0.54 for France, 0.50 for Germany and 0.26 for Italy), confirming the presence of a decoupling in recent years whichever the export growth rate considered.

Figure A1

\section{Y-o-y changes in the volume of goods exports and the PMI new export orders component}

(percentage $y-0-y$ changes in real goods exports;

seasonally-adjusted quarterly averages of PMIs minus 50)

\section{Italy}

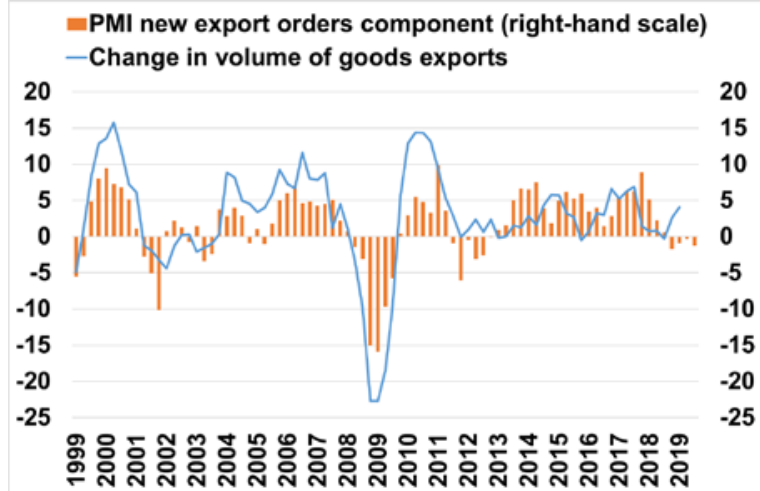

Germany

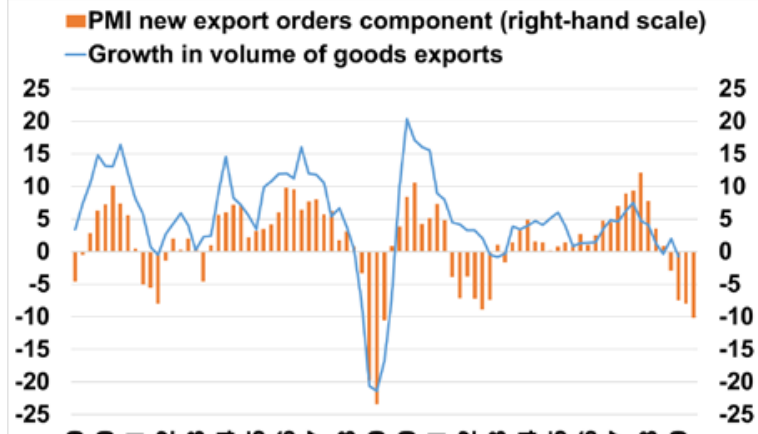

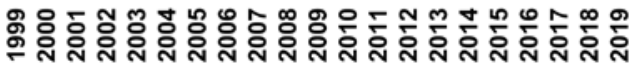

France

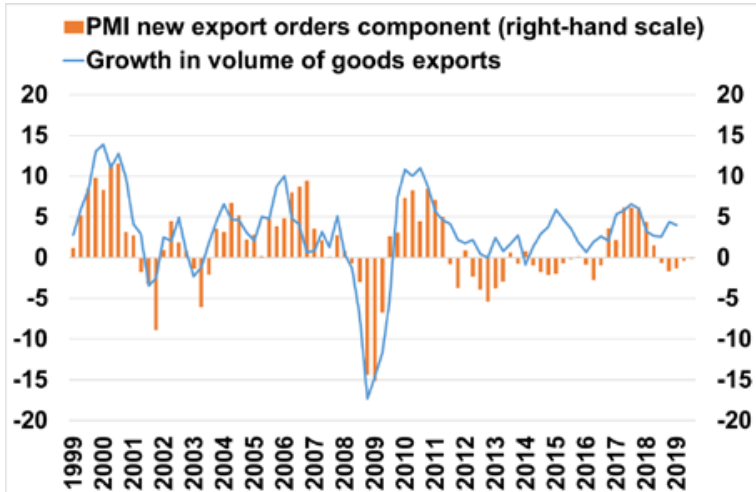

Spain

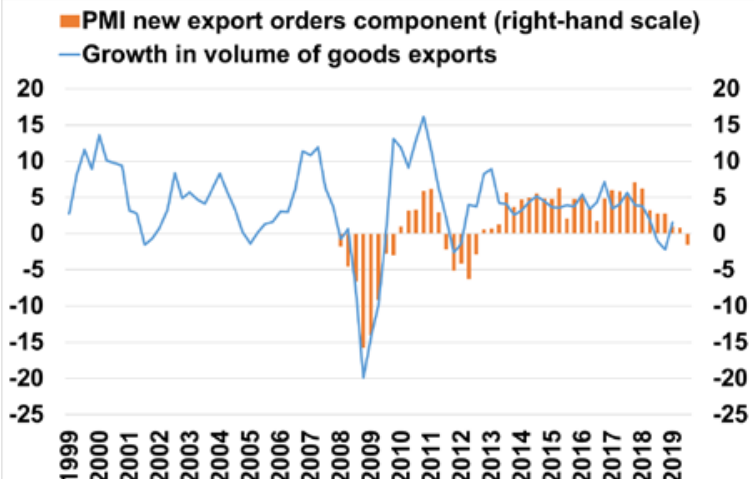

Source: Eurostat for national account data and Markit for PMI series.

16 In this case the lagged PMI indicator displays a larger correlation with export growth than the contemporaneous measure. 


\section{Bibliography}

Ahir, H., Bloom, N. and Furceri, D. (2018), "World Uncertainty Index", Stanford mimeo.

Aprigliano, V. (2011), "The relationship between the PMI and the Italian index of industrial production and the impact of the latest economic crisis", Bank of Italy Working Papers 820.

Bachmann, R., Elstner, S., and Sims, E.R. (2014), "Uncertainty and economic activity: evidence from business survey data", American Economic Journal: Macroeconomics 5(2), pp. 217-249.

Baker, S.R., Bloom, N. and Davis, S.J. (2016), "Measuring Economic Policy Uncertainty", The Quarterly Journal of Economics 131(4), pp. 1593-1636.

Bugamelli, M., Fabiani, S., Federico, S., Felettigh, A., Giordano, C. and Linarello, A. (2018), "Back on track? A macro-micro narrative of Italian exports", Italian Economic Journal 4, pp. 1-31.

Busetti, F., Giordano, C. and Zevi, G. (2016), "Drivers of Italy's Investment Slump During the Double Recession", Italian Economic Journal 2(2), pp. 143-165.

Conti, A.M. and Rondinelli, C. (2015), "Tra il dire e il fare: il divario tra giudizi degli imprenditori e andamenti della produzione nell'industria", Bank of Italy Occasional Papers 258.

Gamberoni, E., Giordano, C. and Lopez-Garcia, P. (2016), "Capital and labour (mis) allocation in the euro area: Some stylized facts and determinants", Bank of Italy Occasional Papers 349.

Giordano, C., Marinucci, M. and Silvestrini, A. (2019), "The macro determinants of firms' and households' investment: evidence from Italy", Economic Modelling 78, pp. 118-133.

Guglielminetti, E. (2018), "Confidence and Economic Fluctuations", Bank of Italy mimeo. 